\title{
Efficacy and cost benefit of inhaled corticosteroids in patients considered to have mild asthma in primary care practice
}

\author{
PAUL O'BYRNE MB, LAUREN CUDDY MA*, D WAYNE TAYLOR MA, STEPHEN BIRCH PhD, \\ JOANNE MORRIS MSc ${ }^{\dagger}$, JERRY SYROTUIK MA* \\ Asthma Research Group, Department of Medicine, and Department of Clinical Epidemiology \\ and Biostatistics, McMaster University, Hamilton, *Innovus Inc, Hamilton, \\ ${ }^{\dagger}$ Astra Pharma Inc, Mississauga, Ontario
}

P O'Byrne, L Cuddy, DW TAYlor, S Birch, J MORRIS, J SYROTUIK. Efficacy and cost benefit of inhaled corticosteroids in patients considered to have mild asthma in primary care practice. Can Respir J 1996;3(3):169-175.

OBJECTIVE: Inhaled corticosteroids are infrequently used as asthma therapy in patients considered to have mild asthma in primary care practice. The purpose of this study was to determine whether the use of low doses of inhaled corticosteroids (budesonide), supplemented with bronchodilators as needed, provides clinical benefit and is cost beneficial compared with therapy with bronchodilators alone, in patients considered by their physicians in a primary care setting to have mild asthma, not requiring inhaled corticosteroids.

DESIGN: Double-blind, randomized controlled study comparing three parallel treatment groups receiving $400 \mu \mathrm{g}$ or $800 \mu \mathrm{g}$ inhaled budesonide/day or placebo.

SETTING: Seven primary care practices across Canada. PATIENTS: Fifty-seven adult asthmatics considered to have mild asthma not needing inhaled corticosteroids.

OUTCOME MEASURES: Patients recorded morning and evening peak expiratory flow rates (PEFR) and daily asthma symptom scores. Economic data were collected regarding drug and service use and willingness to pay.

RESULTS: Budesonide significantly reduced early morning and nocturnal symptoms and sputum production, and reduced the use of a bronchodilator compared with placebo. The budesonide groups also showed significant improvements in PEFR, before and after bronchodilator. No differences were found between the two dosages of budesonide; however, the study had insufficient power to detect differences between dosages, had they been present. There was a similar frequency of adverse events in all three treatment groups. The willingness-to-pay assessment found that both doses of budesonide were more cost beneficial than placebo.

CONCLUSIONS: These results demonstrate that inhaled budesonide $400 \mu \mathrm{g} /$ day provides better asthma control and is cost beneficial compared with bronchodilators alone in the management of patients with mild asthma who were not considered to need inhaled corticosteroids in primary care practice. (Pour le résumé, voir page 170)

Key Words: Asthma, Bronchodilators, Budesonide, Inhaled corticosteroids

Correspondence and reprints: Dr PMO'Byrne, Department of Medicine, Room 3U1 Health Sciences Centre, McMaster University, 1200 Main Street West, Hamilton, Ontario L8N 3Z5. Telephone 905-521-2100, fax 905-521-5053, e-mail o'byrnep@fhs.mcmaster.ca 


\section{Efficacité et rentabilité des corticostéroïdes en inhalation chez les patients considérés comme légèrement asthmatiques dans une pratique de soins primaires} utilisés en pratique de soins primaires pour traiter des patients considérés comme légèrement asthmatiques. Cette étude visait à déterminer si l'utilisation de faibles doses de corticostéroïdes en inhalation (budésonide) associés à des bronchodilatateurs au besoin, procure un bénéfice clinique, et si elle est rentable par rapport au traitement comprenant seulement des bronchodilatateurs, chez des patients considérés par leurs médecins exerçant dans un établissement de soins primaires, comme souffrant d'asthme léger ne nécessitant pas l'utilisation de corticostéroïdes en inhalation. MODELLE : Essai comparatif randomisé à double insu comparant trois groupes de traitement en parallèle à qui on administre $400 \mu \mathrm{g}$ ou $800 \mu \mathrm{g} /$ jour de budésonide en inhalation ou un placebo.

CONTEXTE : Sept pratiques de soins primaires à travers le Canada.

PATIENTS : Cinquante-sept adultes asthmatiques considérés comme souffrant d'asthme léger ne nécessitant pas l'utilisation de corticostéroïdes en inhalation.
MESURES DES RÉSULTATS : Les patients ont relevé les mesures de leur débit expiratoire de pointe (DEP) du matin et du soir et les scores quotidiens des symptômes asthmatiques. La cueillette des données d'ordre économique portait sur l'utilisation des médicaments et des services, et sur la volonté de payer.

RÉSULTATS : Le budésonide a réduit considérablement les symptômes nocturnes et du petit matin ainsi que la production d'expectorations, et a fait régresser l'emploi d'un bronchodilatateur comparativement au placebo. Les groupes recevant du budésonide ont démontré une amélioration significative des DEP, avant et après l'utilisation d'un bronchodilatateur. On a relevé aucune différence entre les deux posologies de budésonide; cependant, l'essai n'aurait pas pu détecter les différences entre les posologies advenant que ces différences aient été présentes. La fréquence des effets indésirables était similaire dans les trois groupes de traitement. L'évaluation portant sur la volonté de payer a révélé que les deux doses de budésonide s'avéraient plus rentables que le placebo.

CONCLUSIONS : Ces résultats démontrent que l'administration quotidienne de $400 \mu \mathrm{g}$ de budésonide en inhalation permet de mieux maîtriser l'asthme tout en étant rentable comparativement aux bronchodilatateurs utilisés isolément pour traiter les patients souffrant d'asthme léger, et considérés comme ne nécessitant pas de corticostéroïdes en inhalation dans une pratique de soins primaires.
$\mathrm{U}$ ntil recently, the dominant characteristics of asthma were considered to be recurrent episodes of bronchoconstriction. Bronchodilators such as inhaled beta2-agonists or oral theophylline were usually suggested as first-line therapy (1). Treatment was stepped up to include inhaled corticosteroids only if regular use of bronchodilators did not control symptoms. Recent improved understanding that asthma is largely an inflammatory disease of the airways (2-4), even in mild disease, has suggested the early use of medications considered to have anti-inflammatory activities, such as inhaled corticosteroids. Indeed, several recent reports have suggested inhaled corticosteroids or cromones as the treatment for patients with daily symptoms of asthma (5-7). Reasons for this approach include the observations that inhaled corticosteroids prevent asthma symptoms, increase airway calibre, improve airway hyperresponsiveness and reduce the risk of severe exacerbations, even in patients who were not considered to require this treatment (8). This efficacy is gained with doses of inhaled corticosteroids which, in most adults, are free from clinical side effects and do not significantly suppress adrenal cortisol output (9). In a study of newly diagnosed asthmatics, inhaled budesonide has been shown to be an effective first-line treatment compared with an inhaled beta2-agonist (10). Despite these studies demonstrating efficacy and safety, inhaled corticosteroids are still used infrequently in primary care practice as therapy for patients with daily symptoms. This may be due to the belief that inhaled corticosteroids are appropriate only for patients with moderate to severe asthma, or for the treatment of asthma in a tertiary care setting, or because of doubt about cost benefit in mild asthma.

The present study was designed to examine whether the approach of limiting the use of inhaled corticosteroids to pa- tients with moderate to severe asthma is appropriate. It was necessary to undertake the study in primary care practice, to study patients with mild asthma who are not usually referred for asthma management to secondary or tertiary care clinics. In addition, there is no current information on the cost benefit of this treatment approach in mild asthma. For this reason, the study examined the efficacy and cost benefit of inhaled corticosteroids, supplemented with bronchodilators as needed, compared with bronchodilators alone, as treatment of asthma in primary care practice. The study examined patients considered by their primary care physician to have such mild asthma that they would not derive any clinical benefit from inhaled corticosteroids.

\section{PATIENTS AND METHODS}

Study design: The study was a double-blind randomized comparison among three parallel treatment groups followed for four months. Treatment groups received $400 \mu \mathrm{g}$ inhaled corticosteroid (budesonide) per day, $800 \mu \mathrm{g}$ inhaled corticosteroid (budesonide) per day, or an identical-appearing placebo. Patients were stratified into treatment groups based on seasonal or perennial allergy status and randomized into blocks of three at each centre, based on allergy status. No stratification was made based on current asthma therapy. All patients were provided with conventional rescue therapy consisting of inhaled bronchodilators (terbutaline) and inhaled corticosteroid (budesonide). Patients were permitted to use oral theophylline as recommended by the primary care physician; however, the dose was kept constant throughout the study. Assignment of patients to groups was randomly determined by computer-generated code.

Patients: Patients 18 years of age and older with asthma requiring the use of inhaled bronchodilators (Table 1) were re- 
TABLE 1

Baseline demographic data

\begin{tabular}{lccc}
\hline & Placebo & Budesonide $\mathbf{4 0 0} \boldsymbol{\mu g}$ & Budesonide $\mathbf{8 0 0} \mu \mathbf{g}$ \\
\hline Sex (male/female) & $9 / 11$ & $8 / 9$ & $8 / 12$ \\
Age (years) mean \pm SD & $36 \pm 12.7$ & $32 \pm 9.0$ & $37 \pm 17.8$ \\
Weight (kg) mean \pm SD & $71 \pm 11.3$ & $72 \pm 17.1$ & $73 \pm 16.1$ \\
Height (cm) mean \pm SD & $169 \pm 9.3$ & $170 \pm 12.3$ & $168 \pm 8.9$ \\
Duration of asthma (years) mean \pm SD & $6.9 \pm 8.0$ & $10.2 \pm 11.4$ & $10.1 \pm 10.3$ \\
Seasonal allergies expected during the trial (yes/no) & $5 / 15$ & $3 / 14$ & $4 / 16$ \\
Baseline PEFR (L/min) mean \pm SD & $403 \pm 116$ & $381 \pm 112$ & $364 \pm 115$ \\
Asthma treatment & & & 16 \\
Inhaled beta2-agonists (n) & 19 & 3 & 5 \\
Theophyllines (n) & 4 & 0 & 1 \\
Inhaled ipratropium & 0 & 0 & \\
\hline
\end{tabular}

PEFR Peak expiratory flow rate

cruited from the practices of primary care physicians in seven cities across Canada. To be eligible, patients were required to demonstrate variable peak expiratory flow rates (PEFR) measured before and after inhaled bronchodilator, defined as greater than $10 \%$ difference between the highest daily value and the lowest daily value, for a minimum of three days of a seven-day screening period. Patients who had received treatment with inhaled corticosteroids or oral steroids within the past three months, or patients for whom the physician felt inhaled corticosteroids were indicated, were excluded from participation in the study. Thus, the patients were selected by their primary care physician for enrolment into the study because of the presence of such mild asthma that inhaled corticosteroids were not clinically indicated at the time of the screening period. This decision was made by the enrolling physician without specific reference to asthma severity criteria set by the study coordinators.

Procedures: Patients made a total of six visits to the physician's office. At the screening visit, eligibility criteria were reviewed, and the details of the study were explained to the patients, including the information that the purpose of the study was to evaluate whether their asthma control could be improved; patients were then given daily diaries. The second visit occurred one week after the screening visit, and four visits were scheduled once every four weeks thereafter.

Diaries were completed for the one-week screening period and during the two-week period following each scheduled monthly clinic visit. During the first week postvisit, the highest of three PEFR was recorded using a Wright mini peak flowmeter, both before and 10 mins after bronchodilator, in the morning upon awaking and in the evening at approximately 20:00. During the second week postvisit, the highest of three PEFR was recorded only before bronchodilator in the morning and evening. Patients also recorded asthma symptom scores on a four-point scale, and all asthma medications used during the two weeks following each clinic visit. Symptoms assessed included nocturnal symptoms, early morning symptoms, restriction of daily activities and sputum production.

At each clinic visit, PEFR was measured before and after inhaled bronchodilator. The research coordinator checked at each visit to ensure that patients were using the inhalers correctly. Asthma symptoms, the use of bronchodilators, inhaled corticosteroids and oral prednisone to control flare-ups of asthma symptoms were recorded. Patients were also questioned regarding compliance with the study medication since the last visit. All used and unused medications were returned at each visit and new medications were dispensed.

Inhaled study medications were packaged in identical aerosol containers, and contained 200 doses of either corticosteroid or placebo. Corticosteroid treatments were budesonide $100 \mu \mathrm{g} / \mathrm{puff}$ and budesonide $200 \mu \mathrm{g} / \mathrm{puff}$, and placebo treatment was $0 \mu \mathrm{g} / \mathrm{puff}$, all supplied by Astra Pharma Inc. All patients inhaled two puffs of study medication twice a day, in the morning upon awaking and in the evening at approximately 20:00. An extra can of study medication was provided at each visit, in case of malfunction or delay in attending the next scheduled visit. A Nebuhaler (Astra Draco, Lund, Sweden) was supplied to all patients for administration of study medication.

All patients also received an inhaled bronchodilator (terbutaline) to be used for postbronchodilator peak flow measurements, and as required for symptom relief. All bronchodilators that were used during the study period, including inhaled beta2-agonists and oral theophylline, were recorded in the patient diary. The doses of theophylline were kept constant throughout the study.

The treatment of asthma flare-ups was standardized. In cases of uncontrolled symptoms, patients returned to the clinic and were provided with open label budesonide as relief medication. Patients were instructed to take one puff of budesonide $200 \mu \mathrm{g}$ twice a day in conjunction with the trial medication for one week. If symptoms had subsided at the end of the week, relief budesonide was discontinued. If, after two days of relief budesonide, symptoms were not improving, oral prednisone was added.

Statistical analysis: An intention-to-treat analysis of key efficacy outcome variables was performed, which included all patients with their last available assessment carried forward. This approach was taken because of the dropout rate and because this is a conservative analysis, in that it tends to reduce treatment effects; it likely underestimated the real treatment 
TABLE 2

Reasons for failure to complete the trial

\begin{tabular}{lccc}
\hline & Placebo & $\begin{array}{c}\text { Budesonide } \\
\mathbf{4 0 0} \boldsymbol{\mu g}\end{array}$ & $\begin{array}{c}\text { Budesonide } \\
\mathbf{8 0 0} \boldsymbol{\mu g}\end{array}$ \\
\hline $\begin{array}{l}\text { Patient chose to } \\
\text { discontinue }\end{array}$ & 2 & 1 & 6 \\
$\begin{array}{c}\text { Failure to appear for } \\
\text { follow-up }\end{array}$ & 2 & 2 & 2 \\
$\begin{array}{c}\text { Lack of treatment } \\
\text { efficacy }\end{array}$ & 2 & 0 & 0 \\
Protocol violation & 0 & 1 & 0 \\
\hline
\end{tabular}

effect. Comparison of the three study treatment groups on binary outcomes (eg, the number of patients reporting symptoms) was performed using a $\chi^{2}$ test with two degrees of freedom, and the comparison of continuous outcomes (eg, peak flow measurements) was performed using a one-way ANOVA, based on change scores relative to baseline. A one-way ANOVA was preferred over a repeated measures analysis to determine when differences became significant and whether they remained so over time. All P values reported are for nominal significance levels and no adjustment was made for multiple testing.

Economic analysis: The following economic data were also gathered during the course of the trial: type, strength, and quantity of drugs taken during the trial; number of unscheduled visits to the primary care physician and services provided; visits to other physicians or hospital out-patient departments; time off work or school due to asthma symptoms; number of hospital admissions; length of stay of each admission; services received while an in-patient; quantity and type of all laboratory assessments performed; and use of other agency services. Participating physicians were also asked to record service use (drugs, procedures, tests and referrals) initiated by themselves. Other service utilizations were recorded by the patient at monthly clinic visits.

Patients completed a willingness-to-pay questionnaire at the beginning and at the end of the study, as a monetary measure of the value to the individual of the impact of asthma on their lives. At entry to the trial, each patient was asked how much he or she would be willing to pay per week to avoid asthma and all the problems that it brings (11). At the final follow-up visit, each patient was asked whether the impact of asthma on his or her life was less than, the same as or greater than at the start of the study. Patients who indicated that the impact was less were asked how much they would be willing to pay per week to continue taking the drug they had received during the trial. Two approaches were used to assess the validity of the responses. First, only patients reporting that the impact of asthma on their life was less should record positive willingness to pay. Second, for patients who indicated that the impact was less, the willingness to pay amount should be less than the willingness to pay to avoid asthma completely that was recorded at entry to the trial, because the intervention did not provide a complete cure.

The quantity of study drug therapy (budesonide) was

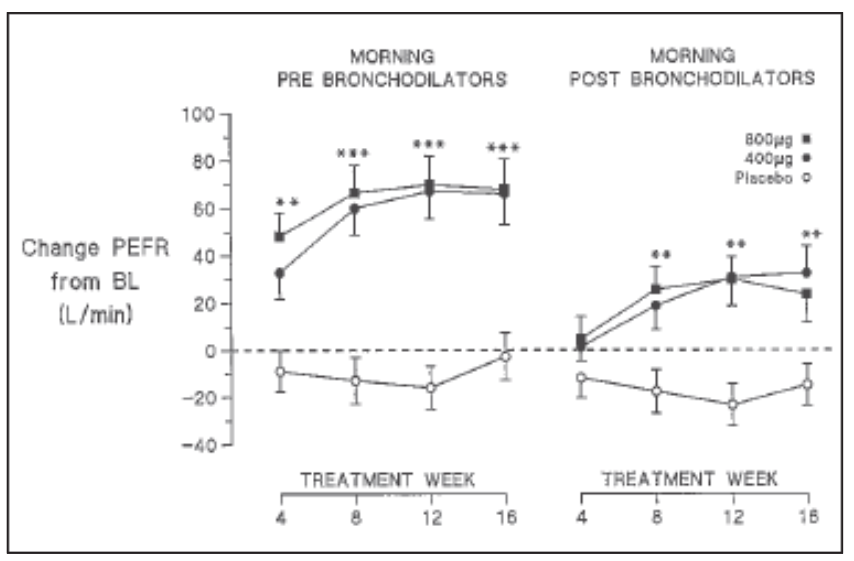

Figure 1) Changes in peak expiratory flow rates (PEFR) from baseline $(B L)$ measured in the morning upon waking both before and after inhaled bronchodilator for treatment weeks 4 to 16 for patients on placebo, budesonide $400 \mu \mathrm{g} / \mathrm{day}$ and $800 \mu \mathrm{g} /$ day. Nominal significance levels are reported, based on one-way ANOVAs between groups. $* * P<0.01 ; * * * P<0.001$

based on the study protocol and multiplied by the unit cost of the drug. The recorded service utilization was costed using a fully allocated hospital costing model in the case of hospital-based services (Chedoke-McMaster Hospital, Hamilton, Ontario), Ontario Hospital Insurance Program (OHIP) fees in the case of physician services (Ontario Ministry of Health) and the best available price for prescribed drugs (Ontario Ministry of Health). Costs of therapy, bronchodilators, and other health care services were aggregated and expressed as a mean cost per patient for each of the three treatment groups. Although some costs were not measured as part of the study (ie, costs to the patient of attending the physician's office), these costs were unlikely to differ markedly among the treatment groups.

\section{RESULTS}

A total of 57 patients from seven centres were entered into the trial. Similar numbers of patients were assigned to each of the three treatment groups (20 placebo, 17 budesonide 400 $\mu \mathrm{g} /$ day and 20 budesonide $800 \mu \mathrm{g} /$ day). No important differences were observed among the three treatment groups at baseline for demographic variables, presence of seasonal allergies, regular treatment of or duration of asthma or baseline PEFR (Table 1).

Eighteen of the 57 patients (32\%) failed to complete the study protocol for reasons listed in Table 2. Although six patients in the high dose budesonide group prematurely terminated the study, only one of those patients reported an adverse event, chest heaviness, as the reason for withdrawal. Only two of the patients, both from the placebo group, stopped treatment due to lack of efficacy. Dropouts were compared with those who remained in the study with regard to baseline characteristics and willingness to pay, and were not found to be significantly different.

Change in PEFR from baseline, as recorded on patient diaries, showed statistically significant improvement with 


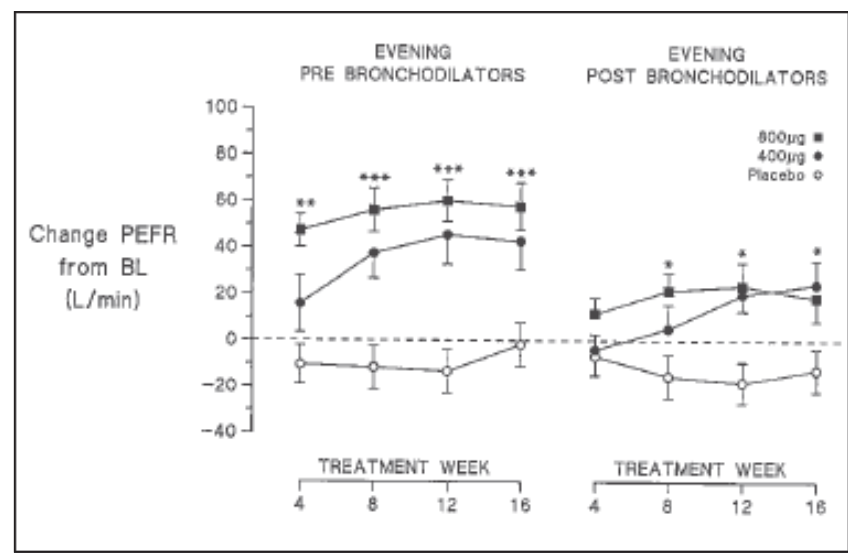

Figure 2) Changes in peak expiratory flow rates (PEFR) from baseline $(B L)$ measured in the evening both before and after inhaled bronchodilator for treatment weeks 4 to 16 for patients on placebo, budesonide $400 \mu \mathrm{g} /$ day and $800 \mu \mathrm{g} /$ day. Nominal significance levels are reported, based on one way ANOVAs between groups. $* P<0.05 ; * * P<0.01 ; * * * P<0.001$

budesonide over placebo. Significant differences were seen in the morning (Figure 1) and evening (Figure 2) both before and after use of a bronchodilator. The magnitude of improvement increased between treatment weeks 4 and 8 and remained relatively stable over the next eight treatment weeks.

The diaries also revealed a reduction in symptom severity with budesonide compared with no change with placebo. Reductions with budesonide were observed in, first, the proportion of patients reporting any symptoms during the past month, which changed from $70 \%, 88 \%$ and $80 \%$ at baseline on placebo, $400 \mu \mathrm{g} /$ day and $800 \mu \mathrm{g} /$ day of budesonide, respectively, to $86 \%, 31 \%$ and $31 \%$ by 12 weeks ( $\mathrm{P}=0.004)$; second, the proportion of patients waking at night with symptoms during the past month, which changed from $30 \%, 65 \%$ and $70 \%$ at baseline to $43 \%, 0 \%$ and $8 \%$, respectively $(\mathrm{P}=0.007)$ (Figure 3$)$; third, the proportion of patients waking early in the morning with symptoms during the past month, which changed from $55 \%, 59 \%$ and $60 \%$ at baseline to $50 \%$, $8 \%$ and $15 \%(\mathrm{P}=0.03)$ (Figure 3); fourth, the proportion of patients reporting a problem with sputum production, which changed from a baseline of $35 \%, 29 \%$ and $35 \%$ to $59 \%, 15 \%$ and $21 \%(\mathrm{P}=0.02)$; and fifth, the proportion of patients reporting the use of bronchodilators more than four times per day for relief of symptoms, which changed from $15 \%, 19 \%$ and $15 \%$ at baseline to $35 \%, 8 \%$ and $0 \%$, respectively $(\mathrm{P}=0.02)$.

Seven asthma exacerbations requiring an increase in treatment in addition to the study treatment were recorded in five patients in the placebo group, while two patients in the budesonide $400 \mu \mathrm{g}$ group and one patient in the budesonide $800 \mu \mathrm{g}$ group had one exacerbation each. Four of the patients, all in the placebo group, needed to attend hospital emergency rooms during six of the exacerbations for the management of acute asthma (Figure 4).

The distribution of adverse medical events, classified by the investigators as serious, was not different among the

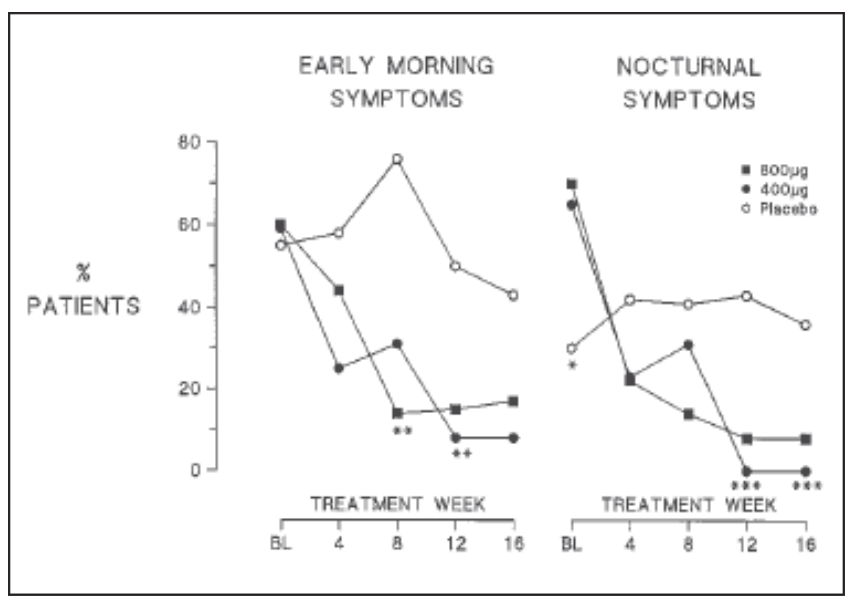

Figure 3) Proportion of patients experiencing early morning symptoms or nocturnal symptoms in the month before evaluation at baseline and at treatment weeks 4 to 16 for patients on placebo, budesonide $400 \mu \mathrm{g} /$ day and $800 \mu \mathrm{g} /$ day. Nominal significance levels are reported, based on one way ANOVAs between groups. $* P<0.05 ; * * P<0.01 ; * * * P<0.001$

study groups. Such events were reported by three patients in the placebo group (all related to increasing asthma symptoms), one patient in the budesonide $400 \mu \mathrm{g} /$ day group (migraine), and two patients in the budesonide $800 \mu \mathrm{g} /$ day group (shakiness, vertigo). The only events considered by the investigators to be serious and not related to the patient's asthma was the migraine reported by a patient on budesonide $400 \mu \mathrm{g} /$ day and severe shaking after taking terbutaline in one patient on budesonide $800 \mu \mathrm{g} /$ day.

A greater proportion of patients in the budesonide groups reported a reduced impact of asthma on their lives at the end of the study than patients in the placebo group $(\mathrm{P}=0.01)$. Mean values of the subjects' willingness to pay for the treatment to relieve their asthma symptoms, in patients who completed the trial, were $\$ 6.25$ (range $\$ 5$ to $\$ 10$ ) per week for placebo, $\$ 23.00$ (range $\$ 12$ to $\$ 50$ ) per week for budesonide $400 \mu \mathrm{g}$ and $\$ 20.00$ (range $\$ 10$ to $\$ 50$ ) per week for budesonide $800 \mu \mathrm{g}$; however, these differences were not statistically significant.

The costs per subject for the study drug was calculated as $\$ 0$ for placebo, $\$ 62.72$ for budesonide $400 \mu \mathrm{g}$, and $\$ 125.44$ for budesonide $800 \mu \mathrm{g}$ for each patient completing the trial. Additional costs for relief medications and all other medical treatments received by these patients increased the costs to $\$ 92.77$ for the placebo group, $\$ 78.88$ for the budesonide $400 \mu \mathrm{g}$ group, and $\$ 140.02$ for the budesonide $800 \mu \mathrm{g}$ group. Compared with placebo, budesonide $400 \mu \mathrm{g}$ produced additional benefit per patient valued at $\$ 268.00(\$ 23.00-\$ 6.25$ willingness to pay per week for 16 weeks). In addition, budesonide $400 \mu \mathrm{g}$ treatment provided an additional net savings in medical treatment costs of $\$ 13.89$ per patient $(\$ 92.77$ - \$78.88). The corresponding data for budesonide $800 \mu \mathrm{g}$ compared with placebo are additional benefits valued at $\$ 220.00$ per patient $(\$ 20.00-\$ 6.25$ willingness to pay per week for 16 weeks) and additional net cost in medical treatment of $\$ 47.25$ ( $\$ 140.02-\$ 92.77)$. In both cases, the values 


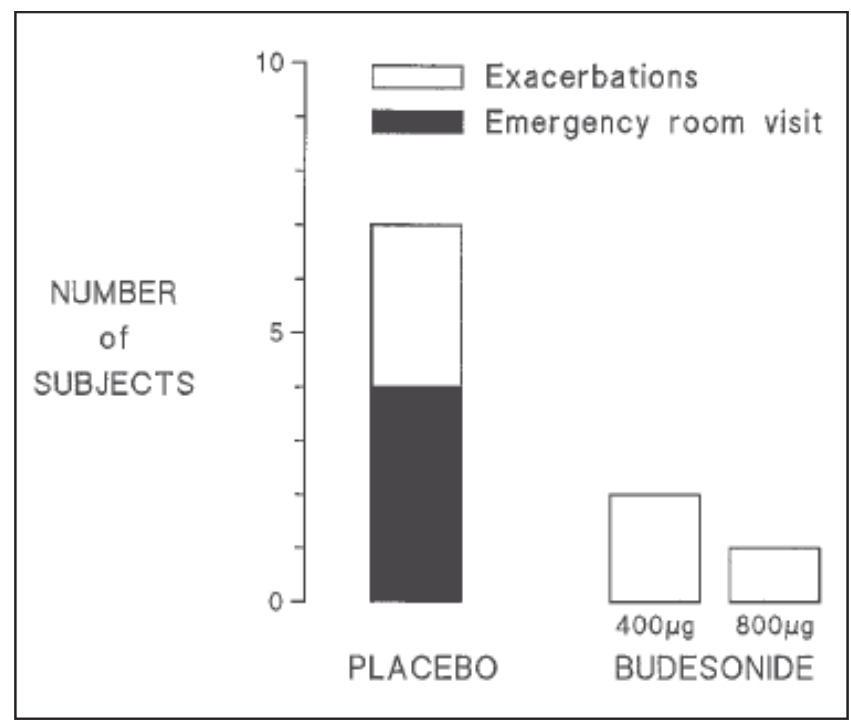

Figure 4) Number of patients experiencing exacerbations of asthma and requiring emergency room visits for treatment of asthma in each of the three treatment arms during the 16 weeks of the study

of the benefits of budesonide exceed the additional costs, indicating that both treatments are cost beneficial, provided that the drug dispensing fees (which were not included in the cost of study treatments), do not exceed the differences between the additional benefits and additional costs.

\section{DISCUSSION}

The primary objective of the present study was to determine whether patients in a primary care setting, who were thought to have such mild asthma as not to require inhaled corticosteroid, would derive clinical benefit from the use of inhaled corticosteroids compared with bronchodilators alone. A secondary objective was to consider the cost benefit aspects of inhaled corticosteroid treatment. The study demonstrated that inhaled budesonide $400 \mu \mathrm{g}$ /day provides better asthma control and is cost beneficial compared with bronchodilators alone in the management of patients considered to have mild asthma in primary care practice, and that, in these patients, no differences could be demonstrated between $400 \mu \mathrm{g} /$ day and $800 \mu \mathrm{g} /$ day of budesonide; however, the study had insufficient power to detect differences between dosages, had they been present. For example, to detect a difference of change of $15 \mathrm{~L} / \mathrm{min}$ in PEFR between patients receiving $400 \mu \mathrm{g} / \mathrm{day}$ and those receiving $800 \mu \mathrm{g} /$ day of budesonide at $80 \%$ power would require 112 patients per treatment group.

Fifty-seven patients were entered into three treatment groups: 20 patients received placebo, 17 received budesonide $400 \mu \mathrm{g} /$ day, and 20 received budesonide $800 \mu \mathrm{g} /$ day. It became apparent once the study commenced that the treatment of mild to moderate asthma was changing among some primary care physicians in Canada. Investigators found patient recruitment difficult because many patients who were screened had received inhaled cortic- osteroids within the previous three months and were thus ineligible for the study.
A second major difficulty encountered was a high dropout rate. Eighteen of 57 patients failed to complete the trial, primarily for reasons unrelated to treatment. Two patients in the placebo group dropped out due to lack of efficacy. The main reason indicated for failure to complete the trial was the patient's choice to discontinue therapy. This may have been due to the commitment required from patients in terms of patient diaries and clinic visits when patients were aware that budesonide was available by prescription.

Budesonide was found to significantly reduce asthma symptoms, sputum production and the use of a bronchodilator compared with placebo. Both budesonide groups also showed significant before and after bronchodilator improvement in PEFR, as well as improvements in symptom severity scores. Five patients in the placebo group required a total of seven visits to hospital emergency rooms to treat asthma, while one patient in the budesonide $400 \mu \mathrm{g}$ group and two patients in the budesonide $800 \mu \mathrm{g}$ group required extra visits to a physician. These frequencies were too low to show a significant difference among treatment groups.

The results of this study are consistent with the results of a number of studies that have demonstrated the efficacy of inhaled corticosteroids in improving symptoms and peak flow rates and reducing bronchodilator use $(8,9)$. The main difference in this study is in the selection of patients from primary care practice, patients in whom the physician believed the regular use of inhaled corticosteroids would not be beneficial. Surprisingly, in this patient population considered too mild to require inhaled corticosteroids by the primary care physician, and in whom self-reported symptoms were mild at the start of the study, $40 \%$ to $60 \%$ of the patients in the budesonide treatment groups were experiencing nocturnal or early morning symptoms in the month before entering the study (Figure 3). These symptoms suggest that asthma control was not optimal. The decrease in these percentages to less than $10 \%$ over the course of the study, together with the mean 60 to $70 \mathrm{~L} / \mathrm{min}$ increase in PEFR morning and evening, and the elimination of exacerbations of asthma requiring emergency room management, indicate that clinically useful improvements were achieved in this patient population with a dose of budesonide as low as $400 \mu \mathrm{g} /$ day. Indeed, it is possible that these benefits could be obtained with even lower doses of inhaled budesonide. These results agree with a recently published study, in which the asthmatic patients selected were not considered by pulmonary specialists to require regular inhaled corticosteroids (8). A dose of 400 $\mu \mathrm{g} /$ day of inhaled budesonide virtually eliminated symptoms and the need for inhaled beta2- agonists, and improved airway responsiveness and flow rates. Thus, optimal control of asthma, as defined in consensus reports on the treatment of asthma (5-7), can be achieved in patients with mild daily symptoms by low doses of inhaled corticosteroids.

The economic evaluation found that both doses of budesonide were more cost beneficial than placebo. Patients receiving budesonide had a greater probability and greater magnitude of improvement than patients receiving placebo. The $800 \mu \mathrm{g}$ dose of budesonide provided no additional bene- 
fits over the $400 \mu \mathrm{g}$ dose but cost more; however, there was insufficient power in the study to detect a difference between these two doses of budesonide, had one existed. In addition, the willingness-to-pay assessment found that at the end of the study significantly more patients in the budesonide groups reported a reduction of the impact of asthma on their life than did patients in the placebo group.

The present study supports the early use of inhaled corticosteroids for adult patients with regular daily symptoms of asthma, and suggests that low doses (budesonide $400 \mu \mathrm{g}$ /day or possibly less) are effective in the management of asthmatic patients with mild to moderate asthma. In addition, the study reinforces the need to strive for optimal control of asthma and, once control is achieved, to identify the minimum amounts of medication needed to maintain control. Lastly, this study has demonstrated, for the first time, that inhaled corticosteroid treatment is more cost beneficial than asthma therapy with bronchodilators alone in patients considered by their physicians to have mild asthma.

ACKNOWLEDGEMENTS: This study was supported by Astra Draco Inc. Participating primary care physicians were Dr Richard Kelly, Pierrefonds Medical Center, Montreal, Quebec; Dr David Vincent, Avenue Medical Centre, Brantford, Ontario; Dr David Ross, Oshawa Clinic, Oshawa, Ontario; Dr Douglas Myhre, Haig Clinic, Lethbridge, Alberta; Dr Judith Stringer, St George Health Centre, Toronto, Ontario; Dr Vincent Peschisolido, Surrey Medical Centre, Scarborough, Ontario; and Dr PE Hoogerwerf, Cannon Clinic, Abbotsford, British Columbia. PM O'Byrne is a senior scientist of the Medical Research Council of Canada.

\section{REFERENCES}

1. Rebuck AS, Chapman KR. Asthma: 2. Trends in pharmacologic therapy. Can Med Assoc J 1987;136:483-8.

2. O'Byrne PM. Airway inflammation and asthma In: O'Byrne PM, ed. Asthma as an Inflammatory Disease. New York: Marcel Dekker, Inc, 1990:143-57.

3. Kirby JG, Hargreave FE, Gleich GJ, O’Byrne PM. Bronchoalveolar cell profiles of asthmatic and nonasthmatic subjects. Am Rev Respir Dis $1987 ; 136: 379-83$.

4. Beasley R, Roche WR, Roberts JA, Holgate ST. Cellular events in the bronchi in mild asthma and after bronchial provocation. Am Rev Respir Dis 1989;139:806-17.

5. Hargreave FE, Dolovich J, Newhouse MT. The assessment and treatment of asthma: a conference report. J Allergy Clin Immunol 1990;85:1098-111.

6. British Thoracic Society, Research Unit of the Royal College of Physicians of London, King's Fund Centre, National Asthma Campaign. Guidelines for management of asthma in adults: I - chronic persistent asthma. BMJ 1990;301:651-4.

7. National Heart, Lung, and Blood Institute, National Institutes of Health. Guidelines for the diagnosis and management of asthma. US Department of Health and Human Services Publication No 91-3042. Bethesda: National Institutes of Health, 1991.

8. Juniper EF, Kline PA, Vanzieleghem MA, Ramsdale EH, O'Byrne PM, Hargreave FE. Effect of long-term treatment with inhaled corticosteroids on airway hyperresponsiveness and clinical asthma in nonsteroid dependent asthmatics. Am Rev Respir Dis 1990;142:832-6.

9. Johannson SA, Andersson KE, Brattsand R, Gruvstad E, Hednes P. Topical and systemic glucocorticoid potencies of budesonide and beclomethasonedipropionate in man. Eur J Clin Pharmacol 1982;22:523-9.

10. Haahtela TH, Jarvinen M, Tuomo K, et al. Comparison of a B2 agonist, terbutaline, with an inhaled corticosteroid, budesonide, in newly detected asthma. N Engl J Med 1991;325:388-92.

11. Thompson M, Reid L, Liang M. Feasibility of willingness-to-pay measurement in chronic arthritis. Med Decis Making 1984;4:195-215. 


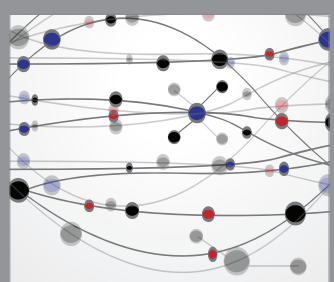

The Scientific World Journal
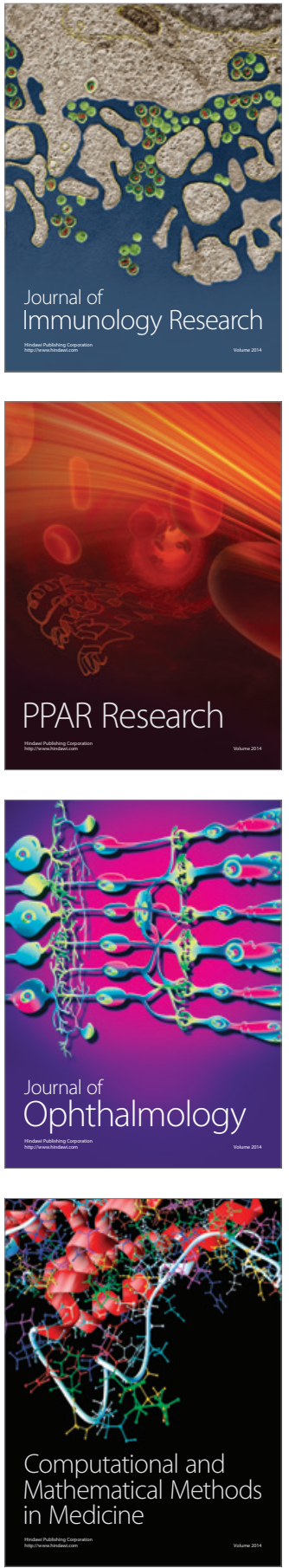

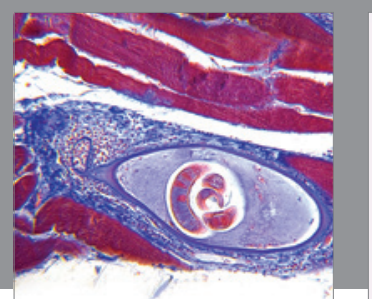

Gastroenterology Research and Practice

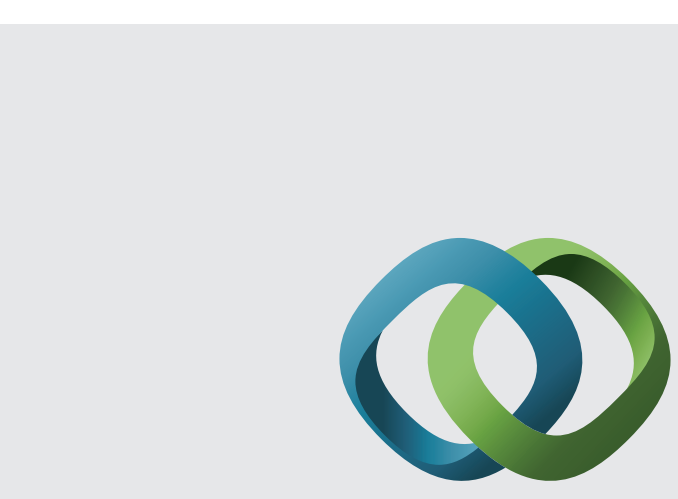

\section{Hindawi}

Submit your manuscripts at

http://www.hindawi.com
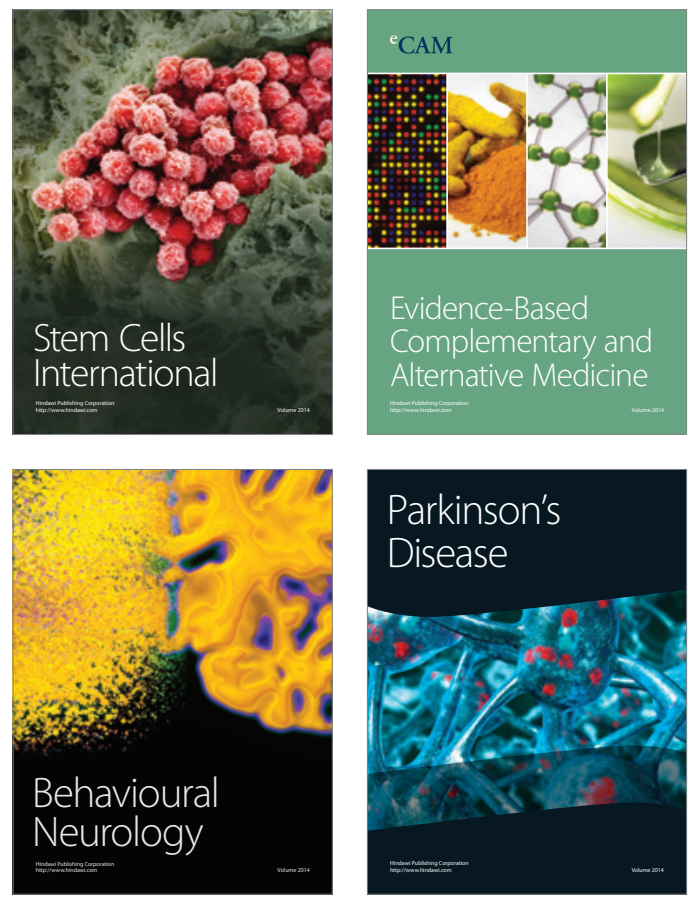
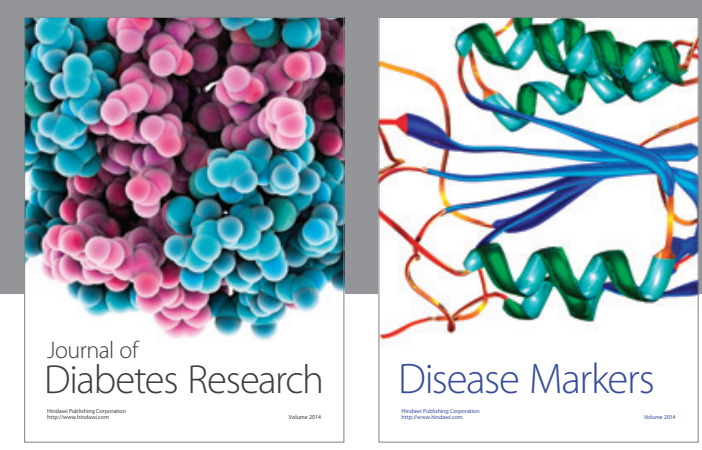

Disease Markers
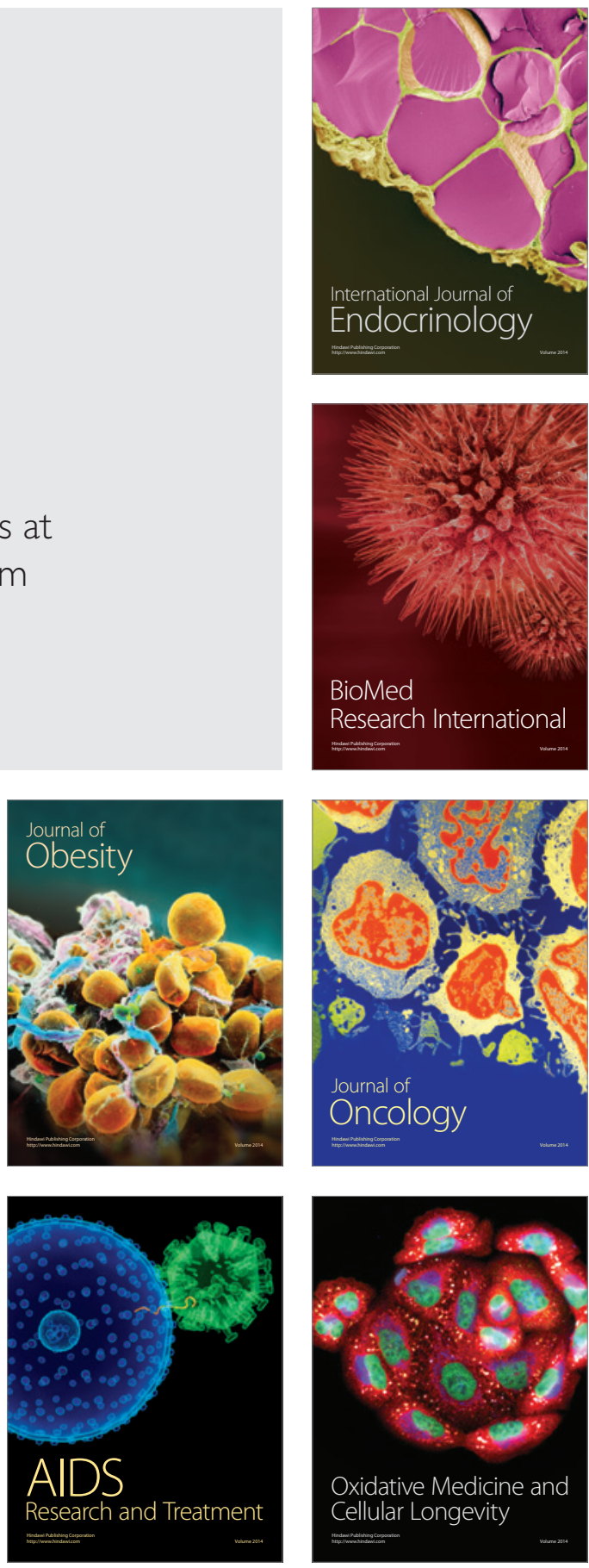